\title{
BMJ Open Cross-sectional, descriptive study of Chagas disease among citizens of Bolivian origin living in Munich, Germany
}

\author{
Miriam Navarro, ${ }^{1}$ Nicole Berens-Riha, ${ }^{2}$ Stefan Hohnerlein, ${ }^{2}$ Peter Seiringer, ${ }^{2,3}$ \\ Charlotte von Saldern, ${ }^{2}$ Sarah Garcia, ${ }^{2}$ Teresa Blasco-Hernández, ${ }^{4,5}$ \\ Bárbara Navaza, ${ }^{1}$ Jonathan Shock, ${ }^{6}$ Gisela Bretzel, ${ }^{2}$ Michael Hoelscher, ${ }^{2,3}$ \\ Thomas Löscher, ${ }^{2}$ Pedro Albajar-Viñas, ${ }^{7}$ Michael Pritsch ${ }^{2,3}$
}

To cite: Navarro M, BerensRiha N, Hohnerlein S, et al. Cross-sectional, descriptive study of Chagas disease among citizens of Bolivian origin living in Munich, Germany. BMJ Open 2017;7: e013960. doi:10.1136/ bmjopen-2016-013960

- Prepublication history and additional material is available. To view please visit the journal (http://dx.doi.org/ 10.1136/bmjopen-2016013960).

MN and NB-R contributed equally.

Received 29 August 2016 Revised 30 October 2016 Accepted 8 December 2016

CrossMark

For numbered affiliations see end of article.

Correspondence to Dr Michael Pritsch; pritsch@|rz.uni-muenchen.de

\section{ABSTRACT}

Purpose: Chagas disease (CD) has become a global health issue mainly due to migration. Germany lacks surveillance data and is home to a large Latin American immigrant population. Recognising that Bolivia is the country with the highest CD prevalence in Latin America, this cross-sectional, descriptive pilot study investigated $C D$ and associated factors among citizens of Bolivian origin living in Munich, Germany.

Methods: Participants completed a questionnaire in order to collect socioeconomic and health-related data. In addition, serology was performed. In case of positive serological tests, PCR diagnostic and clinical staging together with disease management was initiated. Qualitative research was conducted to identify personal and community barriers as well as strategies to increase $C D$ awareness among the population at risk.

Results: Between June 2013 and June 2014, 43 people from Bolivia (or descendants) were enrolled. A total of $9.3 \%$ (4/43), of whom two women were of childbearing age, tested seropositive (ELISA and IFAT), and one also by PCR. For 2/4 positive participants, clinical evaluation was performed and the indeterminate form of $C D$ was diagnosed. Knowledge about CD symptoms and ways of transmission were completely absent among $55.8 \%$ (24/43, 2/4 with CD) and $30.2 \%(13 / 43,1 / 4$ with $C D)$ of participants, respectively. A total of $27.9 \%$ (12/43, $0 / 4$ with $C D)$ of participants had donated blood prior to the study, whereas $62.8 \%(27 / 43,3 / 4$ with $C D)$ were motivated to donate blood in the future. The qualitative research identified lack of knowledge as well as stigma and fears related to $C D$.

Conclusions: Despite the small number of participants, the prevalence of $C D$ as well as the potential risk of non-vectorial transmission was alarming. Campaigns adapted for Latin American migrants as well as control strategies should be developed and put in place in order to prevent nonvectorial transmission and actively detect cases of $C D$ in Germany.

\section{Strengths and limitations of this study}

- Previously undetected cases of Chagas disease -especially among women of childbearing age -were added to the few documented cases in Germany and treatment was initiated.

- Challenges for health professionals and for the health system to reach, diagnose and treat the at-risk population in Germany were evaluated.

- The need for developing and implementing control strategies for Chagas disease in Germany is clearly illustrated.

- The number of individuals in the cohort is small and not representative of the total Bolivian population in Munich or Germany. The most vulnerable group-undocumented Bolivian migrantscould not be reached. Thus, the prevalence of Chagas disease is probably underestimated and all results of this study have to be interpreted carefully.

\section{INTRODUCTION}

Chagas disease (CD) is a potentially lifethreatening infection caused by the protozoan Trypanosoma cruzi. Current estimations are 6-7 million infected humans worldwide. ${ }^{1}$ An initial acute phase of $\mathrm{CD}$ is usually followed by a lifelong asymptomatic chronic phase. About $30 \%$ of chronically infected persons develop organic dysfunctions, mostly cardiac and intestinal manifestations such as dilative cardiomyopathy or megacolon. ${ }^{2}$

Twenty-one Latin American (LA) countries are endemic for $\mathrm{CD}$, and Bolivia is by far the most affected. ${ }^{1}$ However, owing to the increased population mobility, $\mathrm{CD}$ has become an international health issue. ${ }^{1}{ }^{3}$ In 2012, the WHO launched the document "Accelerating work to overcome the global impact of neglected tropical diseases 


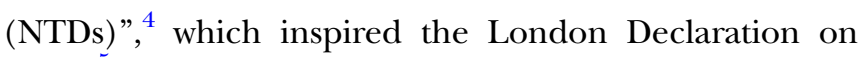
NTDs. ${ }^{5}$

Vector-borne transmission has been the most common way of infection in endemic areas. In non-endemic countries without vectorial transmission, the main risks have been blood transfusions, ${ }^{6}$ organ transplantations ${ }^{7}$ and mother-to-child transmission. ${ }^{8}{ }^{9}$ By 2009, only 4290 of the estimated 68000-122000 people with $\mathrm{CD}$ in Europe had been diagnosed, being the rate of underdiagnosis in Germany is alarmingly high. ${ }^{10}$ In some countries like France, Italy, Spain and Switzerland, epidemiological and preventive studies have already been conducted. ${ }^{11-15}$ The only CD epidemiological investigation in Germany took place in 1997 in Berlin, where 2 of 100 persons were diagnosed. ${ }^{16}$ In 2011, Germany had 154160 registered LA migrants. ${ }^{17}$ Given an estimated $\mathrm{CD}$ prevalence of between 1.3 and $1.7 \%$ in this population group ${ }^{10} 2004$ to 2621 infections could be expected. However, this rough estimation probably underestimates the number; LA migrants without legal status and the growing number of LA migrants moving mainly from Spain to Germany in the past years have not been taken into account (General Consulate of the Plurinational State of Bolivia in Madrid, Spain; personal communication). This alarming lack of CD epidemiological information in Germany suggests limited knowledge about $\mathrm{CD}$ in key groups, such as the affected population itself, healthcare professionals and decisionmakers, and inadequate prevention and management of CD. Control of transfusional, transplantational and congenital transmission of CD in Germany is still insufficient in the context of the European Union recommendations and protocols of other European countries. ${ }^{18-20}$ In Spain, serological screening for population at risk of $T$. cruzi infection has been implemented by law since $2005,{ }^{21}$ and in the USA since 2007.22 In Germany, however, blood donors are only asked if they are suffering from any parasitic infection at present; $\mathrm{CD}$ is mentioned, but guidelines recommend no serological screening for people at risk. Only travellers who visited endemic countries within the previous 6 months are excluded from donating blood ${ }^{23}$ and no routine screening is performed for pregnant women from endemic countries.

The following has been designed as a pilot study, which could be useful for further research and control of the disease, in preparation for a national project called 'ELCiD' (detection and guidance of patients with $\mathrm{CD}$ in Germany), ${ }^{24}$ that started Germany-wide in May 2014.

\section{METHODS}

\section{Objectives}

The objectives of this cross-sectional, descriptive pilot study were:

1. To detect previously undiagnosed cases and determine the prevalence of $\mathrm{CD}$ in a cohort of the Bolivian community living in Munich
2. To evaluate the possibility of the congenital, transfusional and transplantational risk of T. cruzi infection transmission

3. To describe the knowledge, feelings and attitudes related to $\mathrm{CD}$, at the personnel and community level, of people from Bolivia living in Munich

4. To identify possible strategies to overcome barriers to T. cruzi infection prevention and access to healthcare to reach at-risk populations in Germany.

\section{Setting and participants}

The study took place in the outpatient clinic of the Division of Infectious Diseases and Tropical Medicine (DIDTM) in Munich, Germany. Participants were recruited through (1) dissemination of informative leaflets, (2) informative presentations at local Bolivian meeting points (eg, Bolivian consulate) and events within the local Bolivian community, (3) social media, as well as (4) the outpatient clinic of DIDTM and family doctors' offices. Regarding inclusion criteria, all citizens of Bolivian origin living in the commuter belt (urban railway) of Munich that came to the LMU and gave written informed consent were included. Participants under the age of 18 years were included via written informed consent from their parents. Citizens of Bolivian origin who had neither been in Bolivia nor had a Bolivian mother, and all persons lacking the capacity to give informed consent were excluded. All investigation was conducted according to the principles expressed in the Declaration of Helsinki and participation was free of charge.

\section{Questionnaires and qualitative research}

All participants completed a questionnaire in order to collect socioeconomic and medical data (see online supplementary appendix). All documents were in German and Spanish, and a bilingual (Spanish-German) medical doctor was available for assistance at all times. Concerning qualitative research, two semistructured interviews, a triangular group and one Participatory Action Research (PAR) activity with seven participants was carried out. Qualitative research was conducted in a total of 12 participants. Selection criteria were: those participants in the study who wanted to be interviewed, prior to as well as after performing the serological test. The PAR consisted of an informative workshop about CD given by a medical doctor. All activities were recorded, transcribed and underwent quality control. Open Code 4.02 software was employed for the analysis. Methodological (within-method) and investigator triangulation was performed by three researchers.

\section{CD diagnosis}

Two independent serological tests were performed: in-house-ELISA ${ }^{25}$ and in-house-IFAT. ${ }^{26}$ Only if both test results were concordant were they considered positive or negative. Discordant results should be dealt with individually and solved using a third serological test as well 
as external quality control. After diagnosis, two different PCR tests were performed: a conventional $\mathrm{PCR}^{27}$ and a real-time PCR (Dia.Pro-Diagnostic Bioprobes Srl, Sesto San Giovanni, Italy) test. For external quality control, all positive and $10 \%$ of all negative samples were sent to the Spanish reference laboratory for CD (National Centre of Microbiology, ISCIII). ${ }^{28}$ In summary, positive samples were detected using five different serological methods and additionally tested with three independent PCRs, performed in two different laboratories. Negative samples were confirmed with a minimum of two diverse serological tests at DIDTM, and 10\% of negative samples were confirmed with three additional serological tests at ISCIII.

\section{Staging and management of CD}

Participants diagnosed with CD were offered specialised clinical management by a medical doctor. In order to detect visceral involvement of $\mathrm{CD}$, a complete history as well as physical examination, further laboratory tests, a resting ECG and cardiac ultrasound was performed. All CD-positive patients were counselled not to donate blood or organs, and screening was offered to their relatives. Positive participants were offered antiparasitic treatment based on the WHO recommendations. ${ }^{29} 30$ Benznidazole was used as the first-line medication and was provided by the WHO. During treatment, close monitoring was performed. All positive participants were offered yearly follow-up visits including history, physical examination and an ECG.

\section{Statistical analyses}

Data were entered via double data entry into tables (Microsoft Excel, V.14.3.1). Individual data were analysed using STATA (V.11). For calculation of $p$ values, $\chi^{2}$ and Student's t-tests were used, where appropriate. If data were found to be skewed, a Mann-Whitney rank sum test was used. $p$ Values of $<0.05$ were considered statistically significant. Knowledge about CD symptoms was grouped into categories: 'none', 'poor' (one symptom named), 'intermediate' (more than one symptom named) and 'good' (three frequent symptoms named). Knowledge about ways of transmission was grouped into categories such as 'none', 'poor' (one way of transmission named), 'intermediate' (2-3 ways named) and 'good' (4-5 ways named).

\section{RESULTS}

Between June 2013 and June 2014, 43 participants were enrolled, of whom $29(67.4 \%)$ were female. The mean age was 39 years (SD 17.2 years), range $7-76$ years. All participants possessed a valid German residency permit and were of Bolivian (22/43; 51.2\%), German (20/43; $37.2 \%)$, Spanish $(4 / 43 ; 9.3 \%)$ and Italian $(1 / 43 ; 2.3 \%)$ nationalities. Four participants possessed dual citizenship (German and Bolivian). The mean duration of stay outside of Latin America was 19 years (SD 13.7 years).
Emigration from Bolivia generally occurred when the participants were young adults (mean 22 years, SD 2.2). Those who were born in Germany and never went to Bolivia were not included in this analysis; most of them were children.

\section{CD prevalence and association with socioeconomic factors}

There were no discrepancies in any serological tests performed at DIDTM and ISCIII. Four participants $(9.3 \%$, CI $0.26 \%$ to $18.35 \%$ ) tested positive for CD (three women and one man), table 1 . Two of these women were of childbearing age and wanted to get pregnant. One woman was also positive by PCR. The only significant correlations with testing $\mathrm{CD}$ positive and the socioeconomic factors were a higher risk for participants of rural origin $(\mathrm{p}=0.017)$ and participants born to a mother with CD $(\mathrm{p}=0.003)$.

\section{Clinical evaluation and management of CD}

All positive participants were offered a clinical evaluation as well as treatment (where appropriate), free of charge. Only one CD-positive patient (70 years, male) denied the diagnosis and refused further follow-up. One positive female participant had moved abroad (Switzerland) and planned to get clinical evaluation and treatment there. The remaining two positive female participants consisted of a mother (46 years; the only PCR-positive participant) and her daughter (24 years). During clinical evaluation, no symptoms or findings consistent with organ involvement were found and both were diagnosed with the indeterminate stage of $\mathrm{CD}$. Both were treated with benznidazole $(5 \mathrm{mg} / \mathrm{kg}$ per day for 60 days) and tolerated treatment well without adverse events. The initially positive PCR was negative when repeated 3 months after treatment.

\section{Attitudes towards blood/organ donation and medical access}

Most of the participants were motivated to donate blood $(27 / 43 ; 62.8 \% ; 3 / 4$ with CD) and organs (23/43; $53.5 \%$; $3 / 4$ with CD). Nearly all participants had access to regular healthcare in Germany $(38 / 43 ; 88.4 \% ; 3 / 4$ with $\mathrm{CD}$ ); five did not answer this question (table 2).

\section{Knowledge about CD}

Only 30 participants $(69.8 \%$; $3 / 4$ with $\mathrm{CD})$ had previously heard about CD and 24 (55.8\%; 2/4 with CD) had no knowledge of $\mathrm{CD}$ symptoms. The possible presence of $\mathrm{CD}$ without symptoms was falsely denied by two participants; one of them had CD. Most of the participants $(40 / 43 ; 93.0 \%$; $4 / 4$ with $\mathrm{CD})$ had never undergone a CD test before (table 3$)$.

\section{Qualitative research}

Knowledge about CD

Participants focused mainly on insect and congenital transmission table 4. Otherwise, large confusion and a 
Table 1 Socioeconomic factors and CD status

\begin{tabular}{|c|c|c|c|}
\hline & $\begin{array}{l}\text { Total number of } \\
\text { participants: } n=43(\%)\end{array}$ & $\begin{array}{l}\text { Participants tested } \\
\text { T. cruzi-: } n=39(\%)\end{array}$ & $\begin{array}{l}\text { Participants tested } \\
\text { T. cruzi+: } \mathrm{n}=4(\%)\end{array}$ \\
\hline \multicolumn{4}{|l|}{ Sex } \\
\hline Female & $29(67.4)$ & $26(66.7)$ & $3(75.0)$ \\
\hline Male & $14(32.6)$ & $13(33.3)$ & $1(25.0)$ \\
\hline \multicolumn{4}{|l|}{ Country of birth } \\
\hline Bolivia & $29(67.4)$ & $26(66.7)$ & $3(75.0)$ \\
\hline Germany & $12(27.9)$ & $12(30.8)$ & 0 \\
\hline Peru & $1(2.3)$ & $1(2.6)$ & 0 \\
\hline Argentina & $1(2.3)$ & 0 & $1(25.0)$ \\
\hline \multicolumn{4}{|l|}{ Main habitation in Bolivia } \\
\hline La Paz & $15(34.8)$ & $15(38.5)$ & 0 \\
\hline Cochabamba & $10(23.3)$ & $7(17.9)$ & $3(75.0)$ \\
\hline Santa Cruz & $2(4.7)$ & $2(5.1)$ & 0 \\
\hline Sucre/Chuquisaca & $1(2.2)$ & $1(2.6)$ & 0 \\
\hline Potosí & $2(4.7)$ & $2(5.1)$ & 0 \\
\hline Oruro & $3(7.0)$ & $3(7.7)$ & 0 \\
\hline Tarija & $2(4.7)$ & $1(2.6)$ & $1(25.0)$ \\
\hline Bolivian mothers only & $8(18.6)$ & $8(20.5)$ & 0 \\
\hline \multicolumn{4}{|l|}{ Reason for migration to Europe } \\
\hline Work & $4(9.3)$ & $3(7.7)$ & $1(25.0)$ \\
\hline Studies & $19(44.2)$ & $17(43.6)$ & $2(50.0)$ \\
\hline Relationship/marriage & $6(15.0)$ & $5(12.8)$ & $1(25.0)$ \\
\hline Family & $8(18.6)$ & $8(20.5)$ & 0 \\
\hline Other & $6(14.0)$ & $6(15.4)$ & 0 \\
\hline \multicolumn{4}{|l|}{ Area of residence in Latin America } \\
\hline Urban (>10 000 inhabitants) & $36(83.7)$ & $34(87.2)$ & $2(50.0)$ \\
\hline Rural (<10 000 inhabitants) & $4(9.3)$ & $2(5.1)$ & $2(50.0)$ \\
\hline No answer & $3(7.0)$ & $3(7.7)$ & 0 \\
\hline \multicolumn{4}{|l|}{ Material of house during childhood } \\
\hline Stone or cement & $26(60.5)$ & $25(64.1)$ & $1(25.0)$ \\
\hline Adobe & $10(23.3)$ & $8(20.5)$ & $2(50.0)$ \\
\hline Other material & 7 (16.3) & $6(15.4)$ & $1(25.0)$ \\
\hline \multicolumn{4}{|l|}{ 'Vinchuca'-bugs at home } \\
\hline Yes & $11(25.6)$ & $9(23.1)$ & $2(50.0)$ \\
\hline No & $32(74.4)$ & $30(76.9)$ & $2(50.0)$ \\
\hline \multicolumn{4}{|l|}{ Highest educational level } \\
\hline No school completed & $1(2.3)$ & $1(2.6)$ & 0 \\
\hline Primary school & $2(4.7)$ & $2(5.1)$ & 0 \\
\hline Secondary school & $9(20.9)$ & 7 (18.0) & $2(50.0)$ \\
\hline Apprenticeship & $12(27.9)$ & $12(30.8)$ & 0 \\
\hline University & $19(44.2)$ & $17(43.6)$ & $2(50.0)$ \\
\hline \multicolumn{4}{|l|}{ Parents' highest level of education } \\
\hline No school completed & $1(2.3)$ & 0 & $1(25.0)$ \\
\hline Primary school & $2(4.7)$ & $1(2.6)$ & $1(25.0)$ \\
\hline Secondary school & 8 (18.6) & $7(18.0)$ & $1(25.0)$ \\
\hline Apprenticeship & $12(27.9)$ & $11(28.2)$ & $1(25.0)$ \\
\hline University & $20(46.5)$ & $20(51.3)$ & 0 \\
\hline \multicolumn{4}{|l|}{ Chagas disease among relatives } \\
\hline No information & $16(37.2)$ & $17(43.6)$ & $1(25.0)$ \\
\hline No infected relative & $16(37.2)$ & $15(38.5)$ & $1(25.0)$ \\
\hline Mother & $4(9.3)$ & $2(5.1)$ & $2(50.0)$ \\
\hline Father & $2(4.7)$ & $2(5.1)$ & 0 \\
\hline Brother/sister & $1(2.3)$ & $1(2.6)$ & 0 \\
\hline Others (grandparents, uncle) & $4(9.3)$ & $2(5.1)$ & 0 \\
\hline
\end{tabular}

CD, Chagas disease; T. cruzi, Trypanosoma cruzi. 
Table 2 Attitudes towards blood and organ donation and access to healthcare

\begin{tabular}{|c|c|c|c|}
\hline & $\begin{array}{l}\text { Total number of } \\
\text { participants: } n=43(\%)\end{array}$ & $\begin{array}{l}\text { Participants tested } \\
\text { T. cruzi-: } n=39(\%)\end{array}$ & $\begin{array}{l}\text { Participants tested } \\
\text { T. cruzi+: } n=4(\%)\end{array}$ \\
\hline \multicolumn{4}{|l|}{ Attitude towards blood donation } \\
\hline Disposed to donate & $27(62.8)$ & $24(61.5)$ & $3(75.0)$ \\
\hline Not disposed to donate & $6(14.0)$ & $5(12.8)$ & $1(25.0)$ \\
\hline No decision & $10(23.3)$ & $10(25.6)$ & 0 \\
\hline \multicolumn{4}{|l|}{ Former blood donations } \\
\hline Donation in past & $12(27.9)$ & $12(30.8)$ & 0 \\
\hline No donation in past & $31(72.1)$ & 27 (69.2) & $4(100.0)$ \\
\hline \multicolumn{4}{|l|}{ Former received transfusions } \\
\hline Transfusion received & $6(14.0)$ & $5(12.8)$ & $1(25.0)$ \\
\hline No transfusion received & $37(86.1)$ & 34 (87.2) & $3(75.0)$ \\
\hline \multicolumn{4}{|c|}{ Attitude towards organ donation after death } \\
\hline Disposed to donate organs & $23(53.5)$ & $20(51.3)$ & $3(75.0)$ \\
\hline Not disposed to donate organs & $11(25.6)$ & $10(25.6)$ & $1(25.0)$ \\
\hline No decision & 9 (20.9) & $9(23.1)$ & 0 \\
\hline \multicolumn{4}{|c|}{ Access to medical services in Germany } \\
\hline Access without problems & $38(88.4)$ & 35 (89.7) & $3(75.0)$ \\
\hline No answer & $5(11.6)$ & 4 (10.3) & $1(25.0)$ \\
\hline \multicolumn{4}{|l|}{ Type of health insurance in Germany } \\
\hline German public/private insurance & $38(88.4)$ & 35 (89.7) & $3(75.0)$ \\
\hline Insurance of other EU country & $2(4.7)$ & $1(2.6)$ & $1(25.0)$ \\
\hline No answer & $3(7.0)$ & $3(7.7)$ & 0 \\
\hline
\end{tabular}

Table 3 Participants' knowledge about CD

\begin{tabular}{|c|c|c|c|}
\hline & $\begin{array}{l}\text { Total number of } \\
\text { participants: } n=43(\%)\end{array}$ & $\begin{array}{l}\text { Participants tested } \\
\text { T. cruzi-: } \mathrm{n}=39(\%)\end{array}$ & $\begin{array}{l}\text { Participants tested } \\
\text { T. cruzi+: } n=4(\%)\end{array}$ \\
\hline \multicolumn{4}{|c|}{ Previously received information about Chagas disease } \\
\hline Information received in past & $30(69.8)$ & $27(69.2)$ & $3(75.0)$ \\
\hline No information received & $13(30.2)$ & $12(30.8)$ & $1(25.0)$ \\
\hline \multicolumn{4}{|c|}{ Knowledge about three frequent symptoms of chronic Chagas disease } \\
\hline None & $24(55.8)$ & $22(56.4)$ & $2(25.0)$ \\
\hline Little knowledge & $8(18.6)$ & 7 (18.0) & $1(25.0)$ \\
\hline Intermediate knowledge & $6(14.0)$ & $6(15.4)$ & 0 \\
\hline Good knowledge & $5(11.6)$ & $4(10.3)$ & $1(25.0)$ \\
\hline \multicolumn{4}{|c|}{ Possibility of Chagas disease with absence of symptoms } \\
\hline Yes, possible & $23(53.5)$ & $21(53.9)$ & $2(50.0)$ \\
\hline Not possible & $2(4.7)$ & $1(2.6)$ & $1(25.0)$ \\
\hline No knowledge & $18(41.9)$ & $17(43.6)$ & $1(25.0)$ \\
\hline \multicolumn{4}{|c|}{ Knowledge about ways of transmission of Chagas Ddsease } \\
\hline None & $13(30.2)$ & $12(30.8)$ & $1(25.0)$ \\
\hline Little knowledge & $12(27.9)$ & $10(25.6)$ & $2(50.0)$ \\
\hline Intermediate knowledge & 14 (32.6) & 14 (35.9) & 0 \\
\hline Good knowledge & $4(9.3)$ & $3(7.7)$ & $1(25.0)$ \\
\hline \multicolumn{4}{|c|}{ Previously tested for Chagas disease } \\
\hline Tested with positive result & 0 & 0 & 0 \\
\hline Tested with negative result & $3(7.0)$ & $3(7.7)$ & 0 \\
\hline No test performed & $40(93.0)$ & $36(92.3)$ & $4(100.0)$ \\
\hline
\end{tabular}

lack of knowledge about other mechanisms of transmission were reported (Verbatim 1).

All participants knew that symptoms could appear after several years. In general, there was a lot of confusion and lack of understanding on the clinical manifestations (Verbatim 2).
Participants gathered information about CD mainly from friends, relatives and attending physicians, as well as from the internet, press and information received in their home countries. Bolivian associations and the media stood out as being primary resources (Verbatim 3). 
Table 4 Verbatims of interviews, triangular group and participatory action research

\begin{tabular}{ll} 
Code & Verbatim \\
\hline 1 & $\begin{array}{l}\text { It is a parasite that is in the blood, right? (...) it is transmitted because } \\
\text { we were bitten by that bug...that bug bit us... }\end{array}$
\end{tabular}

2 Well, I know that... it is the stomach, the heart and [...], if I am not wrong, it is the liver but l'm not sure.

... but the fact that these two or three Bolivian groups have approached us, they are settled, associated, this has helped to raise awareness. I think it would have been much more difficult without them.

$4 \quad$ I believe that leaflets, with pictures and a bit of information, help quite a lot. We heard you talking about Chagas, and, I mean, I didn't care much [....]. But if a paper is sent to me...not very long, because when you see a lot of information, you take it and throw it away, right? And then it is like, you put it in your pocket, you take it out and take a look at it in the U-Bahn [underground in German] or in any other place. Nowadays, there are cuts in the whole thing and I think it is wrong.

Yes, without the health card, they won't see you, of course. [Question] And... do you know your rights and duties as immigrant here? Hardly.

7 They treat me very nicely, I have a general practitioner who speaks Spanish, the most important thing is that they are always looking after me, they always call me and well, I am grateful.

8 Bolivian man told me about it and I told him: Let's go! They are giving treatment for free, look at the opportunity they are giving us! And he wanted to go but he also told me: "Ok, we need to go but you need time and with my job, what I am going to do? If they call me to work the same day I have the appointment, what I am going to do?

9 They are 60 already and they don't...until now, they didn't have any problem, I don't know...

But... it is the fear with children, too [...] but I don't know what are the odds that I may transmit the disease to my girl, and, if it is possible, how I can control it and prevent it.

13 Of course, because I have travelled a lot around the country, there is always the doubt about...if you got infected, right?

\section{Sociodemographic} data

\section{Categories}

Woman,

Age: 44

Cochabamba

Woman

Age: 48

La Paz

Man

Knowledge about CD

Age: 44

La Paz

Woman

Age: 48

La Paz

Woman

Age: 52

Oruro

Woman

Age: 44

Cochabamba

Woman

Age: 44

Cochabamba

Woman

Age: 44

Cochabamba

Barriers and facilitators to access the healthcare system

Woman

Age: 48

La Paz

Woman

Age: 44

Cochabamba

Woman

Age: 44

Cochabamba

Woman

Age: 48

La Paz

Man

Age: 44

La Paz

\section{$\mathrm{CD}$, Chagas disease.}

Participants' responses confirmed that there is a lot of lack of knowledge about CD. They considered it highly important to inform about $\mathrm{CD}$ at meeting points, such as Bolivian associations, sports events and others. The most effective ways to inform people were audio-visual material, leaflets, via radio; and the key points to focus on were the Spanish parish and the Evangelic Latin Church. It was emphasised that adequate medical information and the help of the health system to encourage people to undergo screening must accompany these activities (Verbatim 4).

\section{Barriers and facilitators of access to the health system}

The obstacles for access to the health system were mainly structural and psychosocial factors, as well as living and working conditions (Verbatim 5).

Participants reported that it was not possible to have a health insurance card without having a contract of 
employment, as well as displaying a lack of knowledge about social resources and immigrant rights in Germany (Verbatim 6).

Generally, there was a high level of satisfaction with the German health system, the physicians being seen as professionals with knowledge about CD (except in one reported case). The individual medical assistance stood out positively, especially when the healthcare professionals spoke Spanish (Verbatim 7).

The precarious working conditions and long working days were described as making it difficult to find a medical consultation compatible; attending a medical consultation could mean an economic loss or even unemployment for the patient (Verbatim 8).

Other barriers included: low acknowledgement of the risk of dying from CD (Verbatim 9); lack of interest and volition of LA people to approach a physician (Verbatim $10)$; and the culture of attending a doctor only in urgent situations (Verbatim 11). The participants pointed out that in combination with the ignorance about $\mathrm{CD}$, these barriers impede access to the health system.

The most important factors to deciding to perform screening were: fear of transmitting CD to someone's own children (Verbatim 12), having relatives or friends suffering from $\mathrm{CD}$, having been in contact with the vector in the past or having lived in rural areas (Verbatim 13).

\section{DISCUSSION}

The prevalence of T. cruzi infection varies according to the locations and the methodology used to reach the population at risk. The prevalence in our study was $9.3 \%$, much lower than in cohorts with previous informational campaigns in Spain and Switzerland (20.9$26.2 \%)^{11} 13$ and in Tropical Medicine Centers in Spain (higher than $30 \%$; due to a selection bias because many patients who attend these consultations already know or have a high suspicion of suffering from CD). ${ }^{8} 2031$ However, it is similar to one study performed among Bolivian blood donors $(10.2 \%)^{32}$ and in a similar study performed in Spain. ${ }^{33}$ The reason could be that the profile of participants is similar in these cohorts, as several participants came from regions with a low prevalence of CD.

Nevertheless, the strength of this initiative lies in the detection of new patients. Up to $93 \%$ of participants (including those with positive serology) had never been tested for CD previously. Probably, in the absence of this programme, the four new patients would still be unaware of their serological status. In fact, Europe is facing a CD underdiagnosis crisis with higher than 95\% of at-risk communities not being tested. ${ }^{10}$ This highlights the need for additional public health measures involving communities from endemic areas.

According to the German Census of 2011, ${ }^{17} 2703$ persons with Bolivian nationality were registered in Germany. Of those, 460 were in Bavaria and 182 in
Munich. The number of German citizens of Bolivian origin in Munich or undocumented Bolivian migrants is unknown. Of the registered Bolivian citizens in Munich, 18/89 (20.2\%) with Bolivian nationality and 4/93 (4.3\%) with dual citizenship could be included in this study. Previous studies indicate that Bolivian migrants without a valid residency permit and health insurance have the highest rate of $\mathrm{CD},{ }^{34}$ but despite serious efforts to reach this population, none could be included. Possible reasons could be fear of detection, no attendance of regular medical services, time incompatibility due to work or lack of knowledge about the possibility of treatment for $\mathrm{CD}$, among others, as observed in other non-endemic countries. ${ }^{35}$ With this in mind, the prevalence of $\mathrm{CD}$ is probably underestimated and all results of this study have to be cautiously interpreted. In addition, the migration of LAs from the Southern to Central Europe has considerably increased in the past few years.

In Germany, treatment of patients with CD poses several challenges: few centres disseminate knowledge regarding the treatment of $\mathrm{CD}$, as national guidelines for screening and treatment are not available. Also, the two drugs currently in use (benznidazole and nifurtimox) are neither registered nor available in Germany. Thus, they are difficult to obtain and have to be used unlicensed. Although it is possible to receive those drugs free of charge from the WHO, during this study their import posed difficulties at DIDTM. It took lengthy correspondence by the medical doctors in charge of treatment with the legal department of DIDTM and the WHO due to a lack of information about legal implications of this process. The absence of specific treatment in Germany needs to be addressed by the scientific community and the health authorities. Structural issues clearly need to be improved as, for example, has been highlighted in the USA. ${ }^{22}$

There is a serious lack of epidemiological data on CD in Germany, with only one study previously published. ${ }^{16}$ Lack of awareness of CD among politicians as well as healthcare personnel, lack of guidelines, treatment know-how, screening measurements and effective transmission control may be some of the consequences of this absence of epidemiological data. ${ }^{22}$ There is an urgent need for broader studies in Germany including more regions/subjects and a higher representativeness of the study population.

Owing to the small number of positive cases in this study, correlations of socioeconomic factors with $\mathrm{CD}$ were not significant. However, participants of rural origin or born from a mother with $\mathrm{CD}$ had a higher risk of $\mathrm{CD}$, which is in concordance with previously conducted studies. ${ }^{13} 3738$

Adequate screening and transmission control measures for $\mathrm{CD}$ in Germany are currently lacking. Healthcare professionals lack awareness of this disease, and thus few tests on $\mathrm{CD}$ are undertaken. There is no screening for pregnant women at risk, nor for blood or 
organ donors. ${ }^{18}$ Coupled with the high willingness to donate blood or organs among the participants, and the women of childbearing age diagnosed through this initiative (two of four of the diagnosed participants), this is alarming. There is no data of non-vectorial transmission of $\mathrm{CD}$ in Germany. However, in several other non-endemic countries, transmission through transfusion, organ transplantation or congenitally has been documented. $^{18}$

A serious lack of information about $\mathrm{CD}$ among Bolivian migrants living in Munich was found from the questionnaire and qualitative research, in agreement with the findings in Spain. ${ }^{8}$ Participants obtained information on $\mathrm{CD}$ mainly through relatives, friends, the media and Bolivian associations. Religious meetings and other social gatherings were mentioned as effective places to disseminate information and graphic materials. These channels have been used successfully in other European countries to reach the population at risk. ${ }^{12} 14$ The perception of risk for CD varied depending on the existence of affected relatives, on past experiences in Bolivia and on the presence/absence of symptoms. ${ }^{34}$ Some cases of discrimination were given in reference to $\mathrm{CD}$, regarding both the social and work environments, as mentioned in endemic countries. ${ }^{39}$ Some of the barriers to getting information about $\mathrm{CD}$ in Munich, observed in this study, were also mentioned in other non-endemic countries, such as lack of knowledge, fear and barriers to accessing healthcare services. ${ }^{11} 223540$

The German healthcare system was generally well respected by participants. However, long waiting lists were seen as a disadvantage due to economic cuts. Problems to coordinate personal and professional lives provided barriers to access healthcare services. Discrimination was felt by one of the participants, both for being affected by CD and for being a newly arrived migrant, which also hinders access to healthcare.

Our small cohort reflects the difficulties in reaching the population at risk when the host country has cultural differences. In order to be effective, future information and awareness campaigns should investigate precisely the previous knowledge and perceptions of CD of the target population as well as the sources of information they employ. After this initiative, participants were less reluctant to reach other participants and encourage them to join the study. This information can be useful for future studies in Germany as well as in other European countries, especially for initiatives or programmes like ELCiD, ${ }^{24}$ which could increase case detection for $\mathrm{CD}$ in non-endemic countries and should be integrated in the common practices of public health programmes.

All mentioned public health measures are critical in order to face the United Nations development goal 3.3 (by 2030, end the epidemics of AIDS, tuberculosis, malaria and neglected tropical diseases... $)^{41}$ with the renewed challenge to detect and eliminate $\mathrm{CD}$ in Germany and in the rest of Europe.
Summing up the limitations of this study, clearly the small number of participants has to be mentioned. Also, the most vulnerable population for $\mathrm{CD}$-Bolivian migrants without a valid residency permit or health insurance-could not be reached and correlations of socioeconomic factors with $\mathrm{CD}$ were impaired due to the small number of positive cases. Thus, the data of this study cannot be generalised and have to be debated very cautiously, especially in the international context. Keeping that in mind, studies like the above could still increase awareness about $\mathrm{CD}$ as well as the difficulties to reach the most vulnerable population groups in Germany as well as in other non-endemic European countries and with this at least contribute to the detection of otherwise undetected cases of CD.

\section{Author affiliations}

${ }^{1}$ Fundación Mundo Sano, Madrid, Spain

${ }^{2}$ Department of Infectious Diseases and Tropical Medicine, Medical Centre of the University of Munich (LMU), Munich, Germany

${ }^{3}$ German Centre for Infection Research (DZIF), partner site Munich, Munich, Germany

${ }^{4}$ Centro Nacional de Medicina Tropical (Instituto de Salud Carlos III), Madrid, Spain

${ }^{5}$ Red de investigación Cooperativa en Enfermedades Tropicales, Madrid, Spain ${ }^{6}$ The Laboratory for Quantum Gravity \& Strings, Department of Mathematics and Applied Mathematics, University of Cape Town, Cape Town, South Africa

${ }^{7}$ Department of Control of Neglected Tropical Diseases, World Health Organization (WHO), Geneva, Switzerland

Acknowledgements The authors thank the participants of this study and the following institutions and people: Honorary Consulate of the Plurinational State of Bolivia in Munich and the Club Illimani (especially Nicolas Resnikowski and Eduardo Berliner). The National Referral Unit for Tropical Diseases, Infectious Diseases Department, Hospital Universitario Ramón y Cajal, Madrid, Spain, especially Dr Pérez-Molina, for his collaboration with Peter Seiringer's training in healthcare of patients with CD. María Flores-Chávez and J. Nieto of the National Centre of Microbiology (Instituto de Salud Carlos III-ISCIII, Spain) for the external quality control of laboratory diagnosis. The Centre of Tropical Medicine (ISCIII), Spain, for its collaboration in the qualitative research.

Contributors NB-R, MN, MH, TL and MP conceived the study and wrote the protocol. SH, NB-R, CvS, SG and MP recruited the participants. SH, NB-R, MN, PS and MP performed the experiments. SH, NB-R, MN, BN, TB-H, JS and MP analysed the data. SH, MN and MP wrote the first draft of the manuscript. All authors contributed to and have approved the final manuscript.

Funding This study was supported through the Clinical Leave Programme (TI 07.001, grant to MP) and the MD Programme (TI 07.003, grant to MP and $\mathrm{MH}$ ) by the German Center for Infection Research (DZIF). The University of Munich (LMU) contributed through the programme 'Lehre@LMU' (grants to MP and CS), and Mundo Sano provided financial and human resources to plan the informational approach to reach the Bolivian community living in Munich and to design and perform the qualitative research.

Competing interests None declared.

Patient consent Obtained.

Ethics approval University of Munich's (LMU) Medical Faculty.

Provenance and peer review Not commissioned; externally peer reviewed.

Data sharing statement The full anonymised data set can be provided on request.

Open Access This is an Open Access article distributed in accordance with the Creative Commons Attribution Non Commercial (CC BY-NC 4.0) license, 
which permits others to distribute, remix, adapt, build upon this work noncommercially, and license their derivative works on different terms, provided the original work is properly cited and the use is non-commercial. See: http:// creativecommons.org/licenses/by-nc/4.0/

\section{REFERENCES}

1. World Health Organization. Epidemiological situation. In: Chagas disease (American trypanosomiasis). World Health Organization, 2015. http://www.who.int/chagas/epidemiology/en (accessed Dec 2015).

2. Rassi A Jr, Rassi A, Marin-Neto JA. Chagas disease. Lancet 2010;375:1388-402.

3. Schmunis GA, Yadon ZE. Chagas disease: a Latin American health problem becoming a world health problem. Acta Trop 2010;115:14-21.

4. World Health Organization. Accelerating work to overcome the global impact of neglected tropical diseases-a roadmap for implementation. 2012. http://apps.who.int/iris/bitstream/10665/70809/ 1/WHO_HTM_NTD_2012.1_eng.pdf (accessed May 2016).

5. World Health Organization. Uniting to combat neglected tropical diseases. London: Declaration on Neglected Tropical Diseases, 2012. http://www.who.int/neglected_diseases/London_Declaration_ NTDs.pdf (accessed May 2016).

6. Benjamin RJ, Stramer SL, Leiby DA, et al. Trypanosoma cruzi infection in North America and Spain: evidence in support of transfusion transmission. Transfusion 2012:52:1913-21.

7. Bern C. Chagas disease in the immunosuppressed host. Curr Opin Infect Dis 2012;25:450-7.

8. Pérez-Ayala A, Pérez-Molina JA, Norman F, et al. Chagas disease in Latin American migrants: a Spanish challenge. Clin Microbiol Infect 2011;17:1108-13.

9. Cevallos AM, Hernández R. Chagas' disease: pregnancy and congenital transmission. Biomed Res Int 2014;2014:401864.

10. Basile L, Jansa JM, Carlier Y, et al. Chagas disease in European countries: the challenge of a surveillance system. Euro Surveil 2011;16:pii: 19968.

11. Navarro M, Pérez-Ayala A, Guionnet A, et al. Targeted screening and health education for Chagas disease tailored to at-risk migrants in Spain, 2007 to 2010. Euro Surveill 2011;16:pii: 19973.

12. Salvador F, Treviño B, Sulleiro E, et al. Trypanosoma cruzi infection in a non-endemic country: epidemiological and clinical profile. Clin Microbiol Infect 2014;20:706-12.

13. Jackson $\mathrm{Y}$, Gétaz L, Wolff $\mathrm{H}$, et al. Prevalence, clinical staging and risk for blood borne transmission of Chagas disease among Latin American migrants in Geneva, Switzerland. PLoS Negl Trop Dis 2010;4:e592.

14. Angheben A, Anselmi M, Gobbi F, et al. Chagas disease in Italy: breaking an epidemiological silence. Euro Surveill 2011;16:pii: 19969.

15. Société de pathologie exotique. Conclusion of the consensus workshop organized by the "Société de pathologie exotique" about the Chagas disease in non-endemic areas. Bull Soc Pathol Exot 2009;102:342-6.

16. Frank M, Hegenscheid B, Janitschke $\mathrm{K}$, et al. Prevalence and epidemiological significance of Trypanosoma cruzi infection among Latin American immigrants in Berlin, Germany. Infection 1997;25:355-8.

17. Sonderauswertung Zensus 2011. Bayrisches Landesamt für Statistik. München, 2015.

18. Requena-Méndez A, Albajar-Viñas $P$, Angheben $A$, et al. Health policies to control Chagas disease transmission in European countries. PLoS Negl Trop Dis 2014;8:e3245.

19. Joint United Kingdom (UK) Blood Transfusion and Tissue Transplantation Services Professional Advisory Committee. South American Trypanosomiasis Risk. In: Donor Selection Guidelines: TDSG-BM 203(17). http://www.transfusionguidelines.org.uk/dsg/bm/ guidelines/so003-south-american-trypanosomiasis-risk (accessed Dec 2015).

20. Navarro M, Navaza B, Guionnet A, et al. Chagas disease in Spain: need for further public health measures. PLoS Negl Trop Dis 2012;6:e1962.

21. Ministerio de Sanidad y Consumo. Real Decreto 1088/2005, de 16 de septiembre, por el que se establecen los requisitos técnicos y condiciones mínimas de la hemodonación y de los centros y servicios de transfusión. Ministerio de Sanidad y Consumo, 2005. http://boe.vlex.es/vid/minimas-hemodonacion-transfusion-17950316 (accessed Dec 2015)

22. Manne-Goehler J, Reich MR, Wirtz VJ. Access to care for Chagas disease in the United States: a health systems analysis. Am J Trop Med Hyg 2015;93:108-13.

23. Bundesärztekammer. Richtlinien zur Gewinnung von Blut und Blutbestandteilen und zur Anwendung von Blutprodukten (Hämotherapie)—Zweite Richtlinienanpassung 2010. Bundesärztekammer, 2010. http://www.bundesaerztekammer.de/ fileadmin/user_upload/downloads/RiliHaemotherapie2010.pdf (accessed Dec 2015).

24. Deutsches Chagas Projekt-EICiD. 2014. http://chagas.info/ (accessed Dec 2015)

25. Knecher LM, Rojkín LF, Capriotti GA, et al. Chagas' disease screening in blood bank employing enzyme immunoassay. Int J Parasitol 1994;24:207-11.

26. Camargo ME. Fluorescent antibody test for the serodiagnosis of American trypanosomiasis. Technical modification employing preserved culture forms of Trypanosoma cruzi in a slide test. Rev Inst Med Trop Sao Paulo 1966;8:227-35.

27. Norman FF, Pérez-Ayala A, Pérez-Molina JA, et al. Lack of association between blood-based detection of Trypanosoma cruzi DNA and cardiac involvement in a non-endemic area. Ann Trop Med Parasitol 2011;105:425-30.

28. Flores-Chávez M, Cruz I, Nieto J, et al. Sensitivity and specificity of an operon immunochromatographic test in serum and whole-blood samples for the diagnosis of Trypanosoma cruzi infection in Spain, an area of nonendemicity. Clin Vaccine Immuno 2012;19:1353-9.

29. World Health Organization. Technical Report Series 905: Control of Chagas disease. 2002. http://apps.who.int/iris/bitstream/10665/ 42443/1/WHO_TRS_905.pdf (accessed May 2016).

30. Bern C. Antitrypanosomal therapy for chronic Chagas' disease. N Engl J Med 2011;364:2527-34.

31. Manzardo C, Treviño B, Gómez i Prat J, et al. Communicable diseases in the immigrant population attended to in a tropical medicine unit: epidemiological aspects and public health issues. Travel Med Infect Dis 2008;6:4-11.

32. Piron M, Vergés M, Muñoz J, et al. Seroprevalence of Trypanosoma cruzi infection in at-risk blood donors in Catalonia (Spain). Transfusion 2008:48:1862-8.

33. Ramos JM, Ponce Y, Gallegos I, et al. Trypanosoma cruzi infection in Elche (Spain): comparison of the seroprevalence in immigrants from Paraguay and Bolivia. Pathog Glob Health 2012;106:102-6.

34. Aguilar SJ. Vivir con Chagas en Madrid: Una exploración antropológica de la experiencia de los pacientes bolivianos con el diagnóstico y atención médica a la enfermedad en un hospital metropolitano español. [MS] Universidad Complutense de Madrid, 2009.

35. Minneman RM, Hennink MM, Nicholls A, et al. Barriers to testing and treatment for Chagas disease among Latino immigrants in Georgia. J Parasitol Res 2012;2012:295034.

36. Navarro M, Navaza B, López-Vélez R. Medical assistance is scarcely sought by immigrants and immigrant-travelers in Spain. J Immigr Minor Health 2013;15:1009-10.

37. Muñoz J, Gómez i Prat J, Gállego M, et al. Clinical profile of Trypanosoma cruzi infection in a non-endemic setting: immigration and Chagas disease in Barcelona (Spain). Acta Trop 2009;111:51-5.

38. Pérez-Ayala A, Pérez-Molina JA, Navarro M, et al. Enfermedad de Chagas en personas procedentes de Latinoamérica residentes en España. In: Migración y Salud. Ministerio de Sanidad y Política Social, 2009. http://www.msssi.gob.es/profesionales/saludPublica/ prevPromocion/promocion/migracion/docs/enfermenfermedad.pdf (accessed Dec 2015)

39. Ventura-Garcia L, Roura M, Pell C, et al. Socio-cultural aspects of Chagas disease: a systematic review of qualitative research. PLoS Negl Trop Dis 2013;7:e2410.

40. Avaria Saavedra A, Gomez i Prat J. Si tengo chagas es mejor que me muera". El desafío de incorporar una aproximación sociocultura a la atención de personas afectadas por Enfermedad de Chagas. Enfermedades Emergentes 2008;10(Suppl 1):40-5.

41. United Nations. 2030 Agenda for Sustainable Development. 17 goals to transform our world. 2016. http://www.un.org/ sustainabledevelopment/health/ (accessed May 2016). 